\title{
Multiple insecticide resistance mechanisms in Anopheles gambiae s.l. populations from Cameroon, Central Africa
}

Philippe Nwane ${ }^{1,2^{*}}$, Josiane Etang ${ }^{1,3}$, Mouhamadou Chouaïbou ${ }^{1,2}$, Jean Claude Toto ${ }^{1}$, Alphonsine Koffi ${ }^{4}$, Rémy Mimpfoundi ${ }^{2}$ and Frédéric Simard ${ }^{5}$

\begin{abstract}
Background: Increasing incidence of DDT and pyrethroid resistance in Anopheles mosquitoes is seen as a limiting factor for malaria vector control. The current study aimed at an in-depth characterization of An. gambiae s.l. resistance to insecticides in Cameroon, in order to guide malaria vector control interventions.

Methods: Anopheles gambiae s.l. mosquitoes were collected as larvae and pupae from six localities spread throughout the four main biogeographical domains of Cameroon and reared to adults in insectaries. Standard WHO insecticide susceptibility tests were carried out with 4\% DDT, 0.75\% permethrin and 0.05\% deltamethrin. Mortality rates and knockdown times $\left(\mathrm{kdt}_{50}\right.$ and $\left.\mathrm{kdt}_{95}\right)$ were determined and the effect of pre-exposure to the synergists DEF, DEM and PBO was assessed. Tested mosquitoes were identified to species and molecular forms (M or S) using PCR-RFLP. The hot ligation method was used to depict $k d r$ mutations and biochemical assays were conducted to assess detoxifying enzyme activities.

Results: The An. arabiensis population from Pitoa was fully susceptible to DDT and permethrin (mortality rates > 98\%) and showed reduced susceptibility to deltamethrin. Resistance to DDT was widespread in An. gambiae s.s. populations and heterogeneous levels of susceptibility to permethrin and deltamethrin were observed. In many cases, prior exposure to synergists partially restored insecticide knockdown effect and increased mortality rates, suggesting a role of detoxifying enzymes in increasing mosquito survival upon challenge by pyrethroids and, to a lower extent DDT. The distribution of $k d r$ alleles suggested a major role of $k d r$-based resistance in the $S$ form of An. gambiae. In biochemical tests, all but one mosquito population overexpressed P450 activity, whereas baseline GST activity was low and similar in all field mosquito populations and in the control.

Conclusion: In Cameroon, multiple resistance mechanisms segregate in the $\mathrm{S}$ form of An. gambiae resulting in heterogeneous resistance profiles, whereas in the $\mathrm{M}$ form and An. arabiensis insecticide tolerance seems to be essentially mediated by enzyme-based detoxification. Synergists partially restored susceptibility to pyrethroid insecticides, and might help mitigate the impact of vector resistance in the field. However, additional vector control tools are needed to further impact on malaria transmission in such settings.
\end{abstract}

\footnotetext{
* Correspondence: philino07@yahoo.fr

'Organisation de Coordination pour la lutte contre les Endémies en Afrique Centrale, P.O. Box 288, Yaoundé, Cameroon

¿Université de Yaoundé I, Yaoundé, Cameroon

Full list of author information is available at the end of the article
} 


\section{Background}

Vector borne diseases account for approximately $17 \%$ of the estimated global burden of infectious diseases and are the major causes of illness and death in tropical and subtropical countries [1]. In most cases, prevention of these diseases relies on vector control, through the use of insecticide treated materials or indoor residual spraying. Although alternative methods include either vaccine or chemotherapy in certain cases, vector control offers the greatest potential for the large-scale reduction of the disease burden [2]. However, the extensive use of insecticides has led to the development of insecticide resistance, making this strategy less effective and limiting the available options for disease prevention and control [3]. For malaria, vector control is chiefly based on the distribution of long-lasting insecticidal nets (LLINs) and/or indoor spraying of houses with residual insecticides (IRS) [4]. The use of these methods is substantially increasing in endemic countries [5] in the framework of malaria elimination programmes [6]. Evidence of malaria burden reduction through full coverage of LLINs or coupled with IRS are reported in some African countries [7-9].

In Cameroon, apart from a few laboratory and field trials carried out in certain locations [10], IRS is not implemented as a large scale malaria vector control measure. However, the National Malaria Control Programme (NMCP) has been scaling up the use of long-lasting insecticidal nets since 2008, with a free mass distribution of $8,654,731$ LLINs branded PermaNet ${ }^{\circledR} 2.0$ and OlysetNet ${ }^{\circledR}$ throughout the country in 2011. This nationwide distribution of LLINs is undertaken in the context where the main malaria-carrying mosquito vectors, including $A n$. gambiae s.s and An. arabiensis are reported to exhibit strong resistance to DDT and pyrethroid insecticides [11,12]. This situation is a major concern considering the Roll Back Malaria universal coverage objective by 2015. Malaria vector resistance to insecticides in Cameroon is conferred by two main mechanisms: (1) an increase of detoxification and/or metabolism through high levels of multi-function oxidases (MFOs), glutathione S-transferases (GSTs) and non-specific esterases (NSEs) [12,13] and (2) alterations at site of action in the sodium channel, viz the $k d r$ mutations $[11,14]$.

The combined effect of target-site insensitivity and metabolic resistance among malaria mosquito populations remains ambiguous. At the present time, questions over the reliability of single $k d r$ genotype in conferring all the variance in resistance phenotype are not unanimously shared in numerous reports [15-18]. Although the impact of $k d r$-based insecticide resistance on the effectiveness of vector control interventions remains to be clearly demonstrated, the knowledge of all operating resistance mechanisms is crucial for success of vector control strategies. Further investigations are therefore needed to assess the co-involvement of $k d r$ mutations with other mechanisms in the resistance phenotypes that were previously reported in Cameroon.

In this study, the susceptibility status of $A n$. gambiae s.l. populations to DDT and pyrethroid insecticides was assessed after exposure to synergists including PBO (4\% pyperonyl butoxide), DEF $(0.25 \%$ S.S.S-tributyl phosphotritioate) and DEM (8\% diethyl maleate) which are known inhibitors of MFOs, NSEs and GSTs, respectively in order to explore the involvement of these detoxifying enzymes in the phenotype of insecticide resistance. Molecular analyses were performed in parallel to assess the association between $k d r$ genotypes and resistance phenotype. Biochemical analyses were also performed to assess cytochrome P450 (i.e. MFO) and GST activities in the tested mosquito populations.

\section{Methods}

\section{Study sites}

Mosquitoes were collected from 6 localities in Cameroon chosen on the basis of the selection pressure reported in previous studies $[18,19]$. These localities belong to the four main biogeographic domains of Cameroon as described in Nwane et al. [14] (Figure 1):

$1)$ in the forest area, two collection sites were selected: Nkolondom (0356 $\left.52^{\prime \prime N}-11^{\circ} 30^{\prime} 18^{\prime} \mathrm{E}\right)$ and Nkolbikon $\left(05^{\circ} 36^{\prime} 06^{\prime \prime} \mathrm{N}-13^{\circ} 40^{\prime} 30^{\prime \prime} \mathrm{E}\right)$. The former is a market gardening area located in the outskirts of Yaoundé (the capital city of Cameroon) and the latter is a suburban area of Bertoua city located in the eastern part of the country;

$2)$ in the coastal area, two collection sites were selected: Bonanloka (04.01'43"N-0943'54"E), an urban area of Douala, the economic capital of Cameroon, and Campo (02 22'30"N-0949'33"E), a rural zone situated southwest of Douala in the coastal region and characterized by intensive forest exploitation and timber storage;

3 ) in the highland area, samples were collected in Makoutchietoum ( $\left.05^{\circ} 36^{\prime} 37^{\prime \prime} \mathrm{N}-10^{\circ} 36^{\prime} 24^{\prime \prime} \mathrm{E}\right)$, a locality with extensive and manual gardening;

4 ) in the northern savanna area, samples were collected in Pitoa $\left(09^{\circ} 23^{\prime} 31^{\prime \prime} \mathrm{N}-13^{\circ} 30^{\prime} 09^{\prime \prime} \mathrm{E}\right)$, a locality surrounded by cotton fields and situated at about $15 \mathrm{~km}$ from Garoua in the northern region of the country.

\section{Mosquito collections}

An. gambiae s.l. larvae and pupae were collected between October 2008 and May 2009. In each collection site, c.a. 30 breeding sites were prospected and larvae were collected and reared locally until adult emergence. Adult mosquitoes were sexed and identified using 


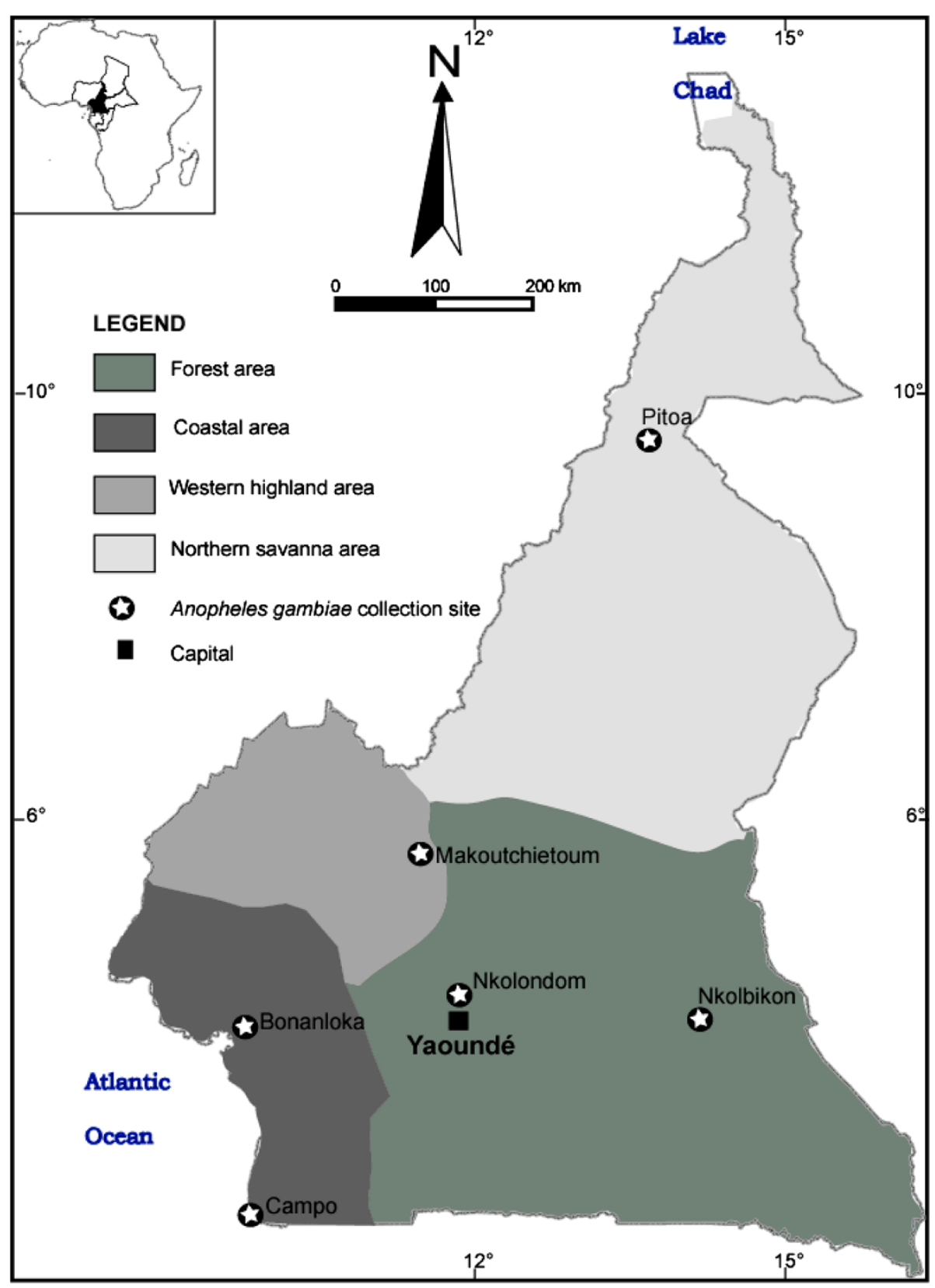

Figure 1 Map of Cameroon showing Anopheles gambiae collection sites.

morphological identification reference keys [20,21]. Only female An. gambiae s.l. were used for bioassays, as well as molecular and biochemical analyses. The Kisumu susceptible strain of An. gambiae was used as a reference strain to compare the susceptibility level of the field collected samples as well as the activity levels of the tested detoxifying enzymes.

\section{Insecticide susceptibility bioassays}

Bioassays were performed on mosquitoes aged 2-4 days using WHO susceptibility test kits and standard protocol for adults [3] under ambient room temperature ranging from $25^{\circ} \mathrm{C}$ to $28^{\circ} \mathrm{C}$ and relative humidity of 70 $80 \%$. Impregnated filter papers with $4 \%$ DDT, $0.05 \%$ deltamethrin and $0.75 \%$ permethrin were supplied by the Vector Control and Research Unit, University Sains Malaysia (Penang, Malaysia). Each full set of bioassays was performed with five batches of 20-25 unfed females: four batches were exposed to insecticide-impregnated filter papers and one batch was exposed to untreated filter paper and served as a control. Tests were concomitantly performed with the Kisumu susceptible reference strain of 
An. gambiae maintained in OCEAC (Yaoundé, Cameroon) insectaries. The number of mosquitoes knocked down was recorded at 5 minute intervals during the $1 \mathrm{~h}$-long exposure and mortality was determined $24 \mathrm{~h}$ post exposure. After completion of the mortality counts, dead and surviving mosquitoes were separately kept on desiccant (silica gel) and stored at $-20^{\circ} \mathrm{C}$ for molecular analyses. Unexposed (control) mosquitoes were also individually kept in $0.5 \mathrm{ml}$ Eppendorf tubes and stored at $-80^{\circ} \mathrm{C}$ for biochemical analyses, together with a batch of unexposed Kisumu specimens.

\section{Synergist bioassays}

Synergist bioassays were performed on adult female mosquitoes using 3 synergists namely $0.25 \%$ S.S.S-tributyl phosphotritioate (DEF, ChemServices West Chester, PA), an inhibitor of esterases, $8 \%$ diethyl maleate (DEM, Sigma Milwaukee, WI), an inhibitor of GSTs and 4\% pyperonyl butoxide (PBO, Sigma Milwaukee, WI), an inhibitor of oxidases. The preparation of stock solutions for each synergist and impregnation on filter papers $(12 \mathrm{~cm} \times 15 \mathrm{~cm})$ were performed in the "Laboratoire de Recherche sur le Paludisme de l'OCEAC (Yaoundé, Cameroon)". For each test run, two treatments were compared: the insecticide alone versus a combination of synergist and insecticide. It is noteworthy highlighting that during the assay including synergist and insecticide, mosquitoes were first exposed for $1 \mathrm{~h}$ to a filter paper impregnated with synergist followed by $1 \mathrm{~h}$ exposure to the insecticide.

\section{Species, molecular forms identification and $k d r$ genotyping}

DNA was extracted from each selected specimen using the method of Collins et al. [22] and each individual was identified to the species level and molecular form using PCR-RFLP [23]. This method allows simultaneous identification of the $\mathrm{M}$ and $\mathrm{S}$ molecular forms within $A n$. gambiae s.s., as well as the other species of the $A n$. gambiae complex. Alleles at the $k d r$ locus were genotyped using hot oligonucleotide ligation assay (HOLA) as described by Lynd et al. [24].

\section{Biochemical assays}

In this study, only mixed function oxidases (MFOs) and glutathione S-transferase (GSTs) activity were evaluated in female mosquitoes aged 2-4 days reared from larvae and never exposed to insecticides but used as control while performing susceptibility tests. Forty-seven specimens were assayed per microtitre plate according to the method described by Hemingway [25].

\section{Statistical analysis}

The knockdown times for $50 \%$ and $95 \%$ of tested mosquitoes $\left(\mathrm{kdt}_{50}\right.$ and $\left.\mathrm{kdt}_{95}\right)$ were estimated using a log- time probit model [26]. Mortality rates were compared between bioassays performed with insecticide alone and after pre-exposure to synergists using Mantel-Haenszel chi-square tests. The rate of suppression of knockdown effect by synergists (kds) was computed as described by Thomas et al. [27] with effective values above 10\%. Biochemical assay data (enzymatic activity per mg of protein) of wild specimens of An. gambiae s.l were compared to the Kisumu susceptible strain using Wilcoxon rank sum test and all computations were performed using $\mathrm{R}$ software (Version 2.15.2, R Development Core Team 2005).

\section{Results}

\section{Resistance phenotypes and the effect of pre-exposure to synergists}

A total of 80 susceptibility tests were performed, including 12 tests with mosquitoes of the reference susceptible strain Kisumu (e.g., 3 tests with DDT, permethrin or deltamethrin alone and 9 combinations whereby mosquitoes were first exposed to the synergist DEF, DEM or $\mathrm{PBO}$ then to the insecticide at the diagnostic dose) and 68 tests with wild samples. Because of low sample sizes in Nkolbikon, some synergist-insecticide combinations could not be performed: DDT was only tested alone and after initial exposure to DEM and mosquitoes exposed to DEM were not tested for susceptibility to the pyrethroids permethrin and deltamethrin.

Throughout the assays, the Kisumu strain of $A n$. gambiae displayed mortality rates above $99 \%$ for the 3 insecticides, with no impact of pre-exposure to synergists (Figure 2). The $\mathrm{kdt}_{50}$ values were 19.1, 9.5 and 8.8 minutes for DDT, deltamethrin and permethrin, respectively; the corresponding $\mathrm{kdt}_{95}$ values were $29.8,17.3$ and 14.6 minutes, respectively and the rates of knockdown time suppression (kdts) were less than $10 \%$ in all cases (not shown).

Field mosquito populations displayed variable levels of resistance to the three insecticides tested (Figure 2A). High mortality to DDT, permethrin and deltamethrin was observed in the Pitoa sample (mortality rate >93\%) and, to a lower extent, in the Bonanloka sample (mortality rate $>82 \%$ ) with low, if any, effect of pre-exposure to synergists on both mortality rates (Figure 2) and $\mathrm{kdt}_{50}$ values (Table 1). In contrast, the mosquito population from Makoutchietoum was highly resistant to DDT and permethrin with mortality rates below $40 \%$, and showed reduced susceptibility to deltamethrin. Pre-exposure to synergists significantly increased mortality to the two pyrethroid insecticides but did not affect resistance to DDT in this population (Figure 2). The $\mathrm{kdt}_{50}$ values for DDT were above $60 \mathrm{~min}$ with and without synergists, whereas pre-exposure to DEF, DEM and PBO led to a significant decrease in $\mathrm{kdt}_{50}$ values for both pyrethroid insecticides (Table 1). A similar pattern was observed in 


\section{A- No Synergist}

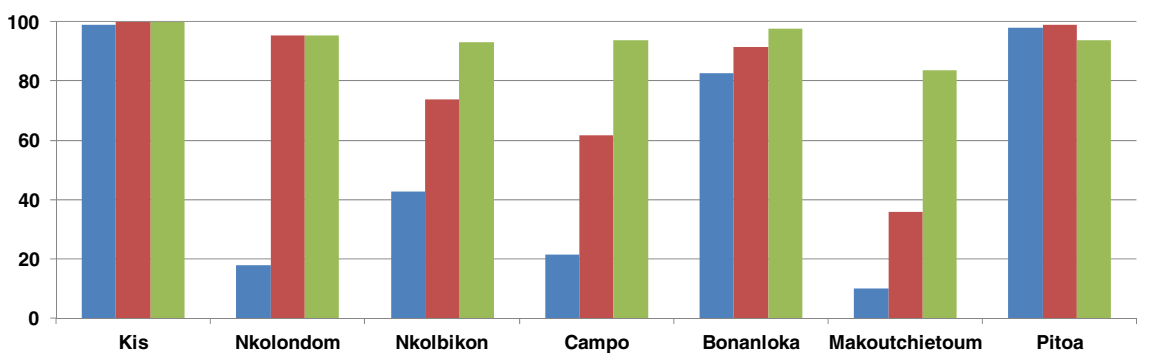

B- DEF
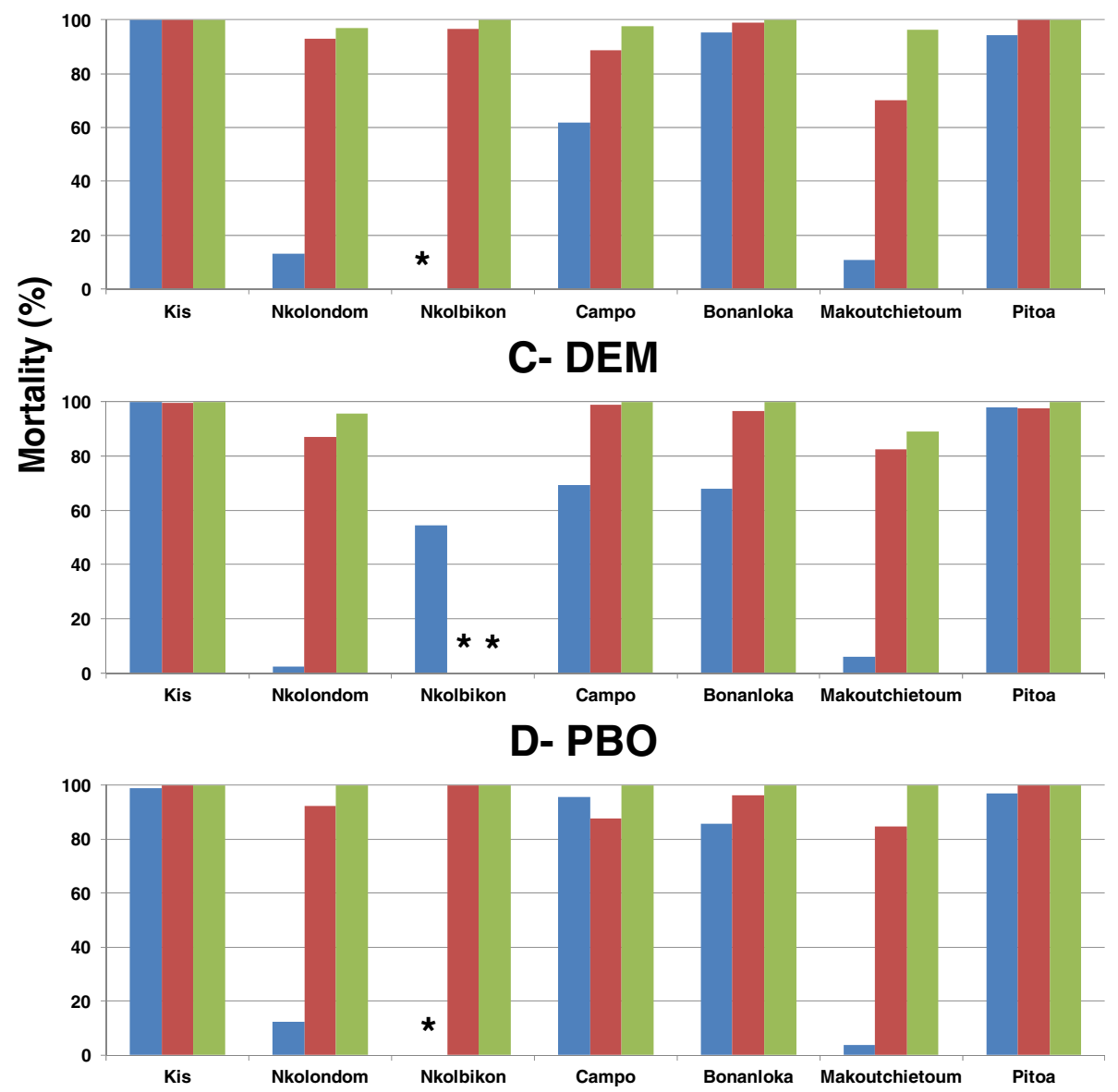

Figure 2 Mortality rates in Anopheles gambiae 24-hours post exposure to 4\% DDT (Blue), $0.75 \%$ permethrin (Red) and $0.05 \%$ deltamethrin (Green) with and without pre-exposure to synergists. (A): No pre-exposure to synergists; (B): Pre-exposure to DEF; (C): Pre-exposure to DEM; (D): Pre-exposure to PBO. * Not determined because the assay was not performed.

Nkolbikon and Campo populations, although mortality to DDT also increased significantly after pre-exposure to synergists in the latter, and especially so with $\mathrm{PBO}$ (Figure 2A and D). Finally in Nkolondom, mortality rates to permethrin and deltamethrin were above $95 \%$ in all treatments, whereas mortality to DDT was dramatically low and remained below 20\% whether or not tested mosquitoes were previously exposed to any of the synergists used in this study.
Mosquito diversity and $k d r$ allelic frequency distribution in insecticide-resistant mosquitoes

Molecular analyses were performed on 721 specimens that were randomly sampled from among survivors to DDT $(\mathrm{N}=417)$, permethrin $(\mathrm{N}=244)$ and deltamethrin $(\mathrm{N}=60)$.

Table 2A shows the distribution of species and molecular forms within An. gambiae s.l. mosquitoes that survived exposure to DDT. In all localities, the $\mathrm{S}$ form of 
Table 1 Knockdown times and percent suppression of knockdown recorded in six Anopheles gambiae. populations from Cameroon

\begin{tabular}{|c|c|c|c|c|c|}
\hline Locality & Test & $\mathrm{N}$ & $\mathrm{kdT}_{50}\left[\mathrm{Cl}_{95}\right](\mathrm{min})$ & $\mathrm{kdT}_{95}\left[\mathrm{Cl}_{95}\right](\mathrm{min})$ & \%kdts \\
\hline \multirow[t]{12}{*}{ Nkolondom } & $4 \% \mathrm{DDT}$ & 92 & $>60$ & $>60$ & \\
\hline & $0.25 \% \mathrm{DEF}+4 \% \mathrm{DDT}$ & 89 & $>60$ & $>60$ & 61.7 \\
\hline & $8 \% \mathrm{DEM}+4 \% \mathrm{DDT}$ & 86 & $>60$ & $>60$ & - \\
\hline & $4 \% \mathrm{PBO}+4 \% \mathrm{DDT}$ & 82 & $>60$ & $>60$ & $<0$ \\
\hline & 0.05\%Delta & 89 & $20.1[17.1-22.8]$ & $45.0[39.0-58.3]$ & \\
\hline & 0.25\%DEF + 0.05\%Delta & 94 & $23.1[22.0-24.1]$ & $42.8[40.4-45.9]$ & $<0$ \\
\hline & 8\%DEM + 0.05\%Delta & 89 & $21.4[20.3-22.3]$ & $37.8[35.5-40.8]$ & $<0$ \\
\hline & $4 \% \mathrm{PBO}+0.05 \%$ Delta & 89 & $20.9[20.0-21.9]$ & $36.6[34.5-39.3]$ & $<0$ \\
\hline & 0.75\%Perm & 83 & $40.2[37.5-42.8]$ & $>60$ & \\
\hline & $0.25 \% \mathrm{DEF}+0.75 \%$ Perm & 87 & $38.1[36.3-40.0]$ & $>60$ & 5.1 \\
\hline & $8 \% \mathrm{DEM}+0.75 \%$ Perm & 85 & $40.0[38.1-42.1]$ & $>60$ & 0.3 \\
\hline & $4 \% \mathrm{PBO}+0.75 \%$ Perm & 90 & $33.8[32.3-45.3]$ & $>60$ & 15.8 \\
\hline \multirow[t]{8}{*}{ Nkolbikon } & $4 \% \mathrm{DDT}$ & 91 & $>60$ & $>60$ & \\
\hline & $8 \% \mathrm{DEM}+4 \% \mathrm{DDT}$ & 86 & $>60$ & $>60$ & $<0$ \\
\hline & 0.05\%Delta & 87 & $17.1[16.1-18.1]$ & $33.7[31.4-36.7]$ & \\
\hline & $0.25 \% \mathrm{DEF}+0.05 \%$ Delta & 62 & $21.1[19.7-22.4]$ & $43.6[40.1-48.4]$ & $<0$ \\
\hline & $4 \%$ PBO + 0.05\%Delta & 87 & $14.1[12.0-16.1]$ & $42.1[36.0-52.0]$ & 17.5 \\
\hline & 0.75\%Perm & 88 & $33.7[30.4-36.9]$ & $>60$ & \\
\hline & $0.25 \% \mathrm{DEF}+0.75 \%$ Perm & 89 & 20.9 [18.9-22.9] & $>60$ & 37.9 \\
\hline & $4 \% \mathrm{PBO}+0.75 \%$ Perm & 87 & $13.7[12.1-21.2]$ & $>60$ & 59.3 \\
\hline \multirow[t]{12}{*}{ Campo } & $4 \% \mathrm{DDT}$ & 87 & $>60$ & $>60$ & \\
\hline & $0.25 \% \mathrm{DEF}+4 \% \mathrm{DDT}$ & 89 & $50.1[44.8-58.1]$ & $>60$ & 51.8 \\
\hline & $8 \% \mathrm{DEM}+4 \% \mathrm{DDT}$ & 85 & $43.8[40.5-47.9]$ & $>60$ & 57.9 \\
\hline & $4 \% \mathrm{PBO}+4 \% \mathrm{DDT}$ & 87 & $43.7[41.1-46.7]$ & $>60$ & 58.0 \\
\hline & 0.05\%Delta & 95 & $13.7[12.7-14.7]$ & $34.1[31.3-37.4]$ & \\
\hline & 0.25\%DEF + 0.05\%Delta & 88 & $14.5[13.6-15.4]$ & $29.9[27.8-32.8]$ & $<0$ \\
\hline & $8 \%$ DEM + 0.05\%Delta & 86 & 17.9 [16.9-18.2] & $29.7[27.9-32.1]$ & $<0$ \\
\hline & 4\%PBO + 0.05\%Delta & 86 & $20.1[19.1-21.1]$ & $36.4[34.2-39.2]$ & $<0$ \\
\hline & 0.75\%Perm & 88 & $37.3[34.1-40.6]$ & $>60$ & \\
\hline & $0.25 \% \mathrm{DEF}+0.75 \%$ Perm & 80 & $22.7[19.2-25.8]$ & $>60$ & 39.1 \\
\hline & $8 \% \mathrm{DEM}+0.75 \%$ Perm & 87 & $47.3[38.8-59.6]$ & $>60$ & $<0$ \\
\hline & $4 \% \mathrm{PBO}+0.75 \%$ Perm & 82 & 15.5 [14.1-16.8] & $41.0[37.3-45.9]$ & 58.4 \\
\hline \multirow[t]{11}{*}{ Bonanloka } & $4 \% \mathrm{DDT}$ & 87 & $37.9[36.5-39.5]$ & $>60$ & \\
\hline & $0.25 \% \mathrm{DEF}+4 \% \mathrm{DDT}$ & 83 & $33.2[31.8-34.6]$ & $>60$ & 12.4 \\
\hline & $8 \%$ DEM + 4\%DDT & 81 & $48.6[46.4-51.2]$ & $>60$ & $<0$ \\
\hline & $4 \% \mathrm{PBO}+4 \% \mathrm{DDT}$ & 84 & 37.9 [34.6-41.9] & $>60$ & 0 \\
\hline & 0.05\%Delta & 78 & 12.8 [10.7-14.7] & $24.1[20.4-31.6]$ & \\
\hline & 0.25\%DEF +0.05\%Delta & 83 & $15.3[12.3-17.9]$ & $31.4[26.0-42.9]$ & $<0$ \\
\hline & $8 \%$ DEM + 0.05\%Delta & 84 & 18.9 [18.0-19.8] & $28.5[26.9-30.7]$ & $<0$ \\
\hline & $4 \% \mathrm{PBO}+0.05 \%$ Delta & 88 & $14.3[11.5-16.8]$ & $29.5[24.4-40.6]$ & $<0$ \\
\hline & 0.75\%Perm & 81 & $15.2[13.2-17.1]$ & $35.3[30.7-42.6]$ & \\
\hline & $0.25 \% \mathrm{DEF}+0.75 \%$ Perm & 92 & 19.5 [18.6-20.4] & $33.9[31.9-36.5]$ & $<0$ \\
\hline & $8 \% \mathrm{DEM}+0.75 \%$ Perm & 89 & $16.1[14.6-17.6]$ & 30.9 [27.8-35.7] & $<0$ \\
\hline
\end{tabular}


Table 1 Knockdown times and percent suppression of knockdown recorded in six Anopheles gambiae. populations from Cameroon (Continued)

\begin{tabular}{|c|c|c|c|c|c|}
\hline & $4 \%$ PBO + 0.75\%Perm & 80 & $12.4[11.2-13.4]$ & $23.8[21.9-26.5]$ & 18.4 \\
\hline \multirow[t]{12}{*}{ Makoutchietoum } & $4 \% \mathrm{DDT}$ & 90 & $>60$ & $>60$ & \\
\hline & $0.25 \% \mathrm{DEF}+4 \% \mathrm{DDT}$ & 81 & $>60$ & $>60$ & 27.7 \\
\hline & $8 \% \mathrm{DEM}+4 \% \mathrm{DDT}$ & 80 & $>60$ & $>60$ & - \\
\hline & $4 \% \mathrm{PBO}+4 \% \mathrm{DDT}$ & 82 & $>60$ & $>60$ & 21.2 \\
\hline & 0.05\%Delta & 86 & $35.3[33.9-36.7]$ & $>60$ & \\
\hline & 0.25\%DEF +0.05\%Delta & 83 & $22.2[21.2-23.1]$ & $34.3[32.6-36.7]$ & 37.1 \\
\hline & $8 \% \mathrm{DEM}+0.05 \%$ Delta & 83 & $30.1[28.9-31.3]$ & $51.8[48.9-55.6]$ & 14.7 \\
\hline & 4\%PBO + 0.05\%Delta & 88 & 30.3 [28.9-31.6] & $>60$ & 14.2 \\
\hline & 0.75\%Perm & 84 & $>60$ & $>60$ & \\
\hline & $0.25 \% \mathrm{DEF}+0.75 \%$ Perm & 89 & $>60$ & $>60$ & 33.7 \\
\hline & $8 \% \mathrm{DEM}+0.75 \%$ Perm & 86 & $>60$ & $>60$ & 36.5 \\
\hline & $4 \% \mathrm{PBO}+0.75 \%$ Perm & 78 & $48.7[46.1-51.9]$ & $>60$ & 50.2 \\
\hline \multirow[t]{12}{*}{ Pitoa } & $4 \% \mathrm{DDT}$ & 100 & 39.3 [37.9-40.6] & $>60$ & \\
\hline & $0.25 \% \mathrm{DEF}+4 \% \mathrm{DDT}$ & 91 & $38.1[36.9-39.3]$ & $58.9[56.1-62.7]$ & 3.1 \\
\hline & $8 \% \mathrm{DEM}+4 \% \mathrm{DDT}$ & 87 & $36.7[35.5-37.9]$ & $58.9[55.9-62.7]$ & 6.6 \\
\hline & $4 \% \mathrm{PBO}+4 \% \mathrm{DDT}$ & 100 & $37.4[33.3-41.2]$ & $>60$ & 4.8 \\
\hline & 0.05\%Delta & 96 & $10.5[8.8-12.1]$ & $21.2[17.9-27.3]$ & \\
\hline & 0.25\%DEF + 0.05\%Delta & 97 & $7.2[6.6-7.7]$ & $13.3[12.1-15.0]$ & 31.4 \\
\hline & $8 \% \mathrm{DEM}+0.05 \%$ Delta & 94 & $9.0[8.3-9.7]$ & $19.2[17.6-21.4]$ & 14.3 \\
\hline & $4 \% \mathrm{PBO}+0.05 \%$ Delta & 100 & 18.6 [17.5-19.8] & $45.4[41.9-49.7]$ & $<0$ \\
\hline & 0.75\%Perm & 81 & $16.8[12.5-20.2]$ & $39.7[32.7-55.2]$ & \\
\hline & $0.25 \% \mathrm{DEF}+0.75 \%$ Perm & 91 & $11.2[9.9-13.6]$ & $32.1[27.4-39.6]$ & 33.3 \\
\hline & $8 \% \mathrm{DEM}+0.75 \%$ Perm & 84 & $18.5[17.5-19.4]$ & $26.8[25.3-28.9]$ & $<0$ \\
\hline & $4 \% \mathrm{PBO}+0.75 \%$ Perm & 94 & $13.1[12.5-13.6]$ & 19.3 [18.1-20.9] & 22.1 \\
\hline
\end{tabular}

Delta: deltamethrin; Perm: permethrin; PBO: pyperonyl butoxide; $D E F$ : S.S.S-tributyl phosphotritioate; DEM: diethyl maleate; $N$ : sample size; kdT ${ }_{50}$ and kdT 95 : knockdown times for $50 \%$ and $95 \%$ of the tested population; \%kdts: percent of knockdown time suppression; Cl95: confidence interval at $95 \%$; min: minute.

An. gambiae was amongst the survivors. In Nkolondom, Nkolbikon and Makoutchietoum, it was the only one member of the complex found amongst DDT survivors, with a high frequency of $k d r$ 1014F resistant allele (f $>0.77)$, presence of the $k d r 1014 S$ resistant allele $(0.02<$ $\mathrm{f}<0.23$ ) and low frequency of the 1014L susceptible allele $(\mathrm{f}<0.11)$. A similar pattern was observed in the $\mathrm{S}$ sample from Campo. However, the 1014L susceptible $k d r$ allele was predominant in the few $\mathrm{S}$ form specimens that survived DDT exposure in Bonanloka and Pitoa ( $\mathrm{f}>0.63$ ), as well as in survivors of the $\mathrm{M}$ form detected in Bonanloka and Campo ( $\mathrm{f}>0.58)$ and An. arabiensis from Pitoa $(\mathrm{f}=1)$.

Table $2 \mathrm{~B}$ and $2 \mathrm{C}$ shows a similar pattern for permethrin and deltamethrin survivors, respectively. As for DDT, the $\mathrm{S}$ form of An. gambiae was widespread amongst permethrin survivors and was found in most study sites. Frequency of the $k d r$ resistant alleles was high in these groups (f $(1014 \mathrm{~F})>0.81$ ) with no occurrence of the 1014L susceptible allele, except in the $\mathrm{S}$ form sample from Bonanloka. Again, the 1014L allele was predominant, and often the only one $k d r$ allele found in $\mathrm{M}$ form specimens from Bonanloka and Campo, as well as in An. arabiensis specimens from Pitoa that survived exposure to pyrethroids.

In summary, the $\mathrm{S}$ form of $A n$. gambiae was widespread and was shown to survive DDT and pyrethroid exposure in most sampled localities. Survival was associated with high frequencies of $k d r$ resistant alleles, especially allele 1014F. In Bonanloka however, the susceptible 1014L allele was found in high frequency in DDT and permethrin survivors and no $S$ form specimen was identified in deltamethrin survivors. $M$ form and An. arabiensis specimens were also identified amongst DDT and permethrin survivors in two and one localities, respectively, with no indication of any correlation with resistant alleles' frequencies at the $k d r$ locus.

\section{Genotype at the $k d r$ locus and resistance to permethrin}

To further explore the relationship between genotype at the $k d r$ locus and resistance phenotype, we compared 
Table 2 Species diversity and allelic frequencies at the $k d r$ locus in survivor mosquitoes exposed to insecticides

\begin{tabular}{|c|c|c|c|c|c|c|}
\hline A- DDT & & $\mathrm{N}$ & $\%$ & $f(1014 L)$ & $f(1014 F)$ & $f(1014 S)$ \\
\hline \multirow[t]{4}{*}{ Nkolondom } & An. gambiae $\mathrm{S}$ & 96 & 100 & 0.03 & 0.95 & 0.02 \\
\hline & An. gambiae M & 0 & 0 & - & - & - \\
\hline & An. arabiensis & 0 & 0 & - & - & - \\
\hline & An. gambiae S & 73 & 100 & 0.11 & 0.78 & 0.11 \\
\hline \multirow[t]{3}{*}{ Nkolbikon } & An. gambiae M & 0 & 0 & - & - & - \\
\hline & An. arabiensis & 0 & 0 & - & - & - \\
\hline & An. gambiae S & 6 & 33 & 0.67 & 0.25 & 0.08 \\
\hline \multirow[t]{3}{*}{ Bonanloka } & An. gambiae M & 12 & 67 & 0.58 & 0.38 & 0.04 \\
\hline & An. arabiensis & 0 & 0 & - & - & - \\
\hline & An. gambiae S & 68 & 85 & 0.00 & 0.79 & 0.21 \\
\hline \multirow[t]{3}{*}{ Campo } & An. gambiae M & 12 & 15 & 0.67 & 0.33 & 0.00 \\
\hline & An. arabiensis & 0 & 0 & - & - & - \\
\hline & An. gambiae S & 135 & 100 & 0.00 & 0.77 & 0.23 \\
\hline \multirow[t]{3}{*}{ Makoutchietoum } & An. gambiae M & 0 & 0 & - & - & - \\
\hline & An. arabiensis & 0 & 0 & - & - & - \\
\hline & An. gambiae S & 4 & 27 & 0.63 & 0.38 & 0.00 \\
\hline \multirow[t]{2}{*}{ Pitoa } & An. gambiae M & 0 & 0 & - & - & - \\
\hline & An. arabiensis & 11 & 73 & 1.00 & 0.00 & 0.00 \\
\hline \multirow[t]{2}{*}{ B- Permethrin } & $N$ & $\%$ & $f(1014 L)$ & $f(1014 F)$ & $f(1014 S)$ & \\
\hline & An. gambiae S & 27 & 100 & 0.00 & 0.98 & 0.02 \\
\hline \multirow[t]{3}{*}{ Nkolondom } & An. gambiae M & 0 & 0 & - & - & - \\
\hline & An. arabiensis & 0 & 0 & - & - & - \\
\hline & An. gambiae S & 20 & 100 & 0.00 & 1.00 & 0.00 \\
\hline \multirow[t]{3}{*}{ Nkolbikon } & An. gambiae M & 0 & 0 & - & - & - \\
\hline & An. arabiensis & 0 & 0 & - & - & - \\
\hline & An. gambiae S & 11 & 22 & 0.82 & 0.18 & 0.00 \\
\hline \multirow[t]{3}{*}{ Bonanloka } & An. gambiae M & 39 & 78 & 0.64 & 0.36 & 0.00 \\
\hline & An. arabiensis & 0 & 0 & - & - & - \\
\hline & An. gambiae S & 52 & 98 & 0.00 & 0.84 & 0.16 \\
\hline \multirow[t]{3}{*}{ Campo } & An. gambiae M & 1 & 2 & 1.00 & 0.00 & 0.00 \\
\hline & An. arabiensis & 0 & 0 & - & - & - \\
\hline & An. gambiae S & 91 & 100 & 0.00 & 0.95 & 0.05 \\
\hline \multirow[t]{3}{*}{ Makoutchietoum } & An. gambiae M & 0 & 0 & - & - & - \\
\hline & An. arabiensis & 0 & 0 & - & - & - \\
\hline & An. gambiae S & 0 & 0 & - & - & - \\
\hline \multirow[t]{2}{*}{ Pitoa } & An. gambiae M & 0 & 0 & - & - & - \\
\hline & An. arabiensis & 3 & 100 & 1.00 & 0.00 & 0.00 \\
\hline \multirow[t]{2}{*}{ C- Deltamethrin } & $N$ & $\%$ & $f(1014 L)$ & $f(1014 F)$ & $f(1014 S)$ & \\
\hline & An. gambiae S & 14 & 100 & 0.00 & 0.96 & 0.04 \\
\hline \multirow[t]{3}{*}{ Nkolondom } & An. gambiae M & 0 & 0 & - & - & - \\
\hline & An. arabiensis & 0 & 0 & - & - & - \\
\hline & An. gambiae S & 5 & 100 & 0.00 & 1.00 & 0.00 \\
\hline \multirow[t]{2}{*}{ Nkolbikon } & An. gambiae M & 0 & 0 & - & - & - \\
\hline & An. arabiensis & 0 & 0 & - & - & - \\
\hline
\end{tabular}


Table 2 Species diversity and allelic frequencies at the $k d r$ locus in survivor mosquitoes exposed to insecticides (Continued)

\begin{tabular}{|c|c|c|c|c|c|c|}
\hline & An. gambiae S & 0 & 0 & - & - & - \\
\hline \multirow[t]{3}{*}{ Bonanloka } & An. gambiae M & 2 & 100 & 1.00 & 0.00 & 0.00 \\
\hline & An. arabiensis & 0 & 0 & - & - & - \\
\hline & An. gambiae S & 8 & 100 & 0.00 & 0.81 & 0.19 \\
\hline \multirow[t]{3}{*}{ Campo } & An. gambiae M & 0 & 0 & - & - & - \\
\hline & An. arabiensis & 0 & 0 & - & - & - \\
\hline & An. gambiae S & 26 & 100 & 0.00 & 0.88 & 0.12 \\
\hline \multirow[t]{3}{*}{ Makoutchietoum } & An. gambiae M & 0 & 0 & - & - & - \\
\hline & An. arabiensis & 0 & 0 & - & - & - \\
\hline & An. gambiae S & 0 & 0 & - & - & - \\
\hline \multirow[t]{2}{*}{ Pitoa } & An. gambiae M & 0 & 0 & - & - & - \\
\hline & An. arabiensis & 5 & 100 & 1.00 & 0.00 & 0.00 \\
\hline
\end{tabular}

the distribution of genotypic frequencies at the $k d r$ locus in permethrin resistant (i.e. 'survivors', $\mathrm{N}=244$ ) and susceptible (i.e. 'dead', $\mathrm{N}=219$ ) mosquitoes. Figure $3 \mathrm{~A}$ shows high genotypic diversity in the $\mathrm{S}$ form samples, with all possible genotypes being represented in most 'dead' samples, whereas paired 'survivors' samples were significantly enriched in 1014F homozygotes $(\mathrm{p}<0.05)$. This supports a role of $k d r$ mutations in shaping resistance to permethrin in these mosquito populations. In the Bonanloka sample however, genotypic diversity was much lower, with only two genotypes identified (i.e. 1014L/1014L and 1014L/1014F, Figure 3A) and no

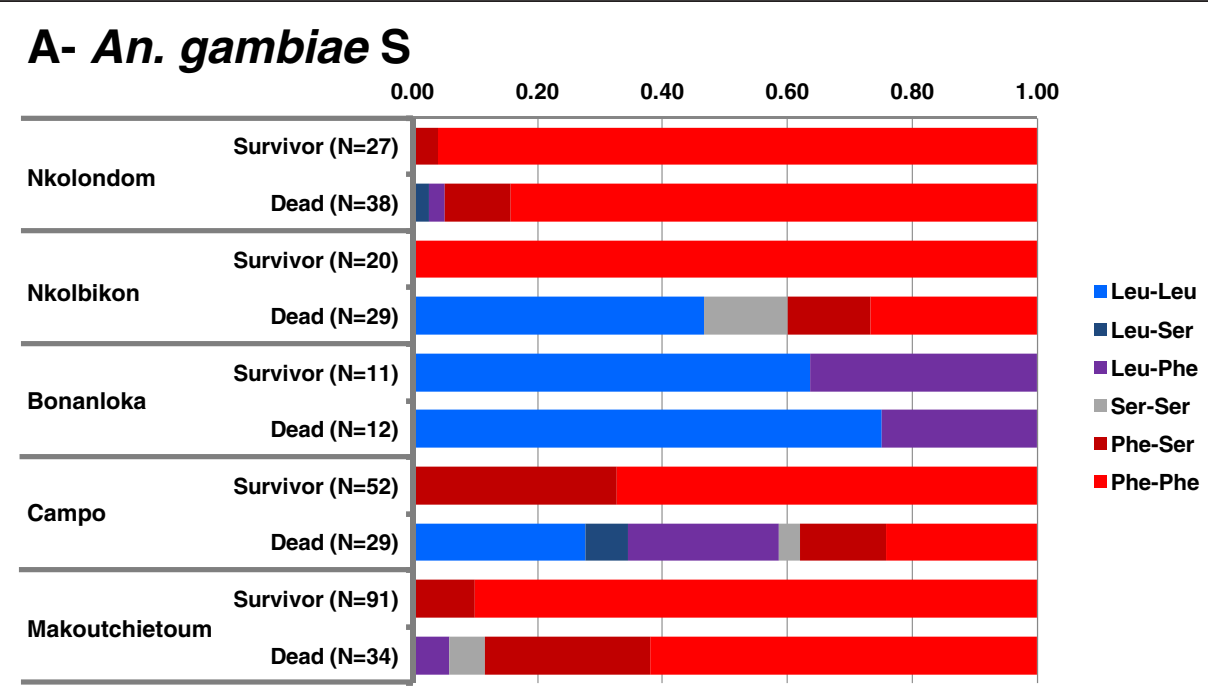

\section{B- An. gambiae M}

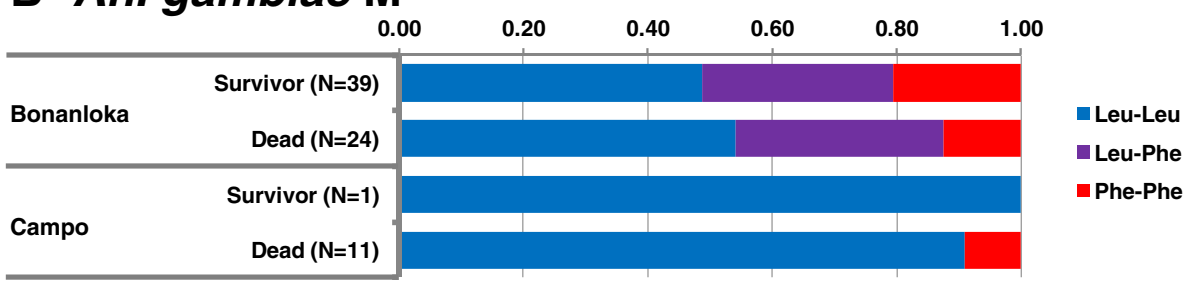

Figure 3 Frequency distribution of the different genotypes at position 1014 of the kdr locus in samples of dead and survivor mosquitoes after exposure to $\mathbf{0 . 7 5 \%}$ permethrin. A) An. gambiae S form; B) An. gambiae $\mathrm{M}$ form. Colour key to the different genotypes is given in the insert on the right. Leu: Leucine at position 1014 (encoded by allele 1014L); Phe: Phenylalanine at position 1014 (encoded by allele 1014F); Ser: Serine at position 1014 (encoded by allele 1014S). 
difference in genotypic frequencies between dead and survivors. Low genetic and genotypic diversity was also observed within the $\mathrm{M}$ form samples from Bonanloka and Campo (Figure 3B) with limited differences in the distribution of genotypic frequencies between dead and survivor groups suggesting limited, if any, role of the $k d r$ mutations in resistance to permethrin in these populations. Furthermore, all An. arabiensis mosquitoes analyzed in this study $(\mathrm{N}=56)$ were from Pitoa and were homozygous for the 1014L susceptible allele.

\section{Mixed function oxidases (MFOs) and glutathione S-transferases (GSTs) activity}

Biochemical assays were successfully performed on samples from 5 out of the 6 studied An. gambiae s.l. populations. Figure 4A shows the mean level of MFOs activity (expressed in cytochrome P450 units) in fieldcollected mosquitoes compared to the reference suscep- tible strain Kisumu. Except in Nkolondom, all sampled populations showed a significantly higher MFOs activity than the susceptible reference strain Kisumu ( $<0.05)$. In contrast, the level of GST activity in these populations was not significantly different $(p>0.05)$ from that of the Kisumu strain (Figure 4B).

\section{Discussion}

This study highlighted the diversity of insecticide resistance phenotypes in Anopheles gambiae s.l. populations from Cameroon. The An. arabiensis population sampled in Pitoa was fully susceptible to DDT and permethrin and showed reduced susceptibility to deltamethrin, as previously reported from this area $[12,19]$. On the other hand, resistance to DDT was widespread in An. gambiae s.s. populations and heterogeneous levels of susceptibility to pyrethroid insecticides permethrin and deltamethrin that rarely reached full susceptibility were observed. This is
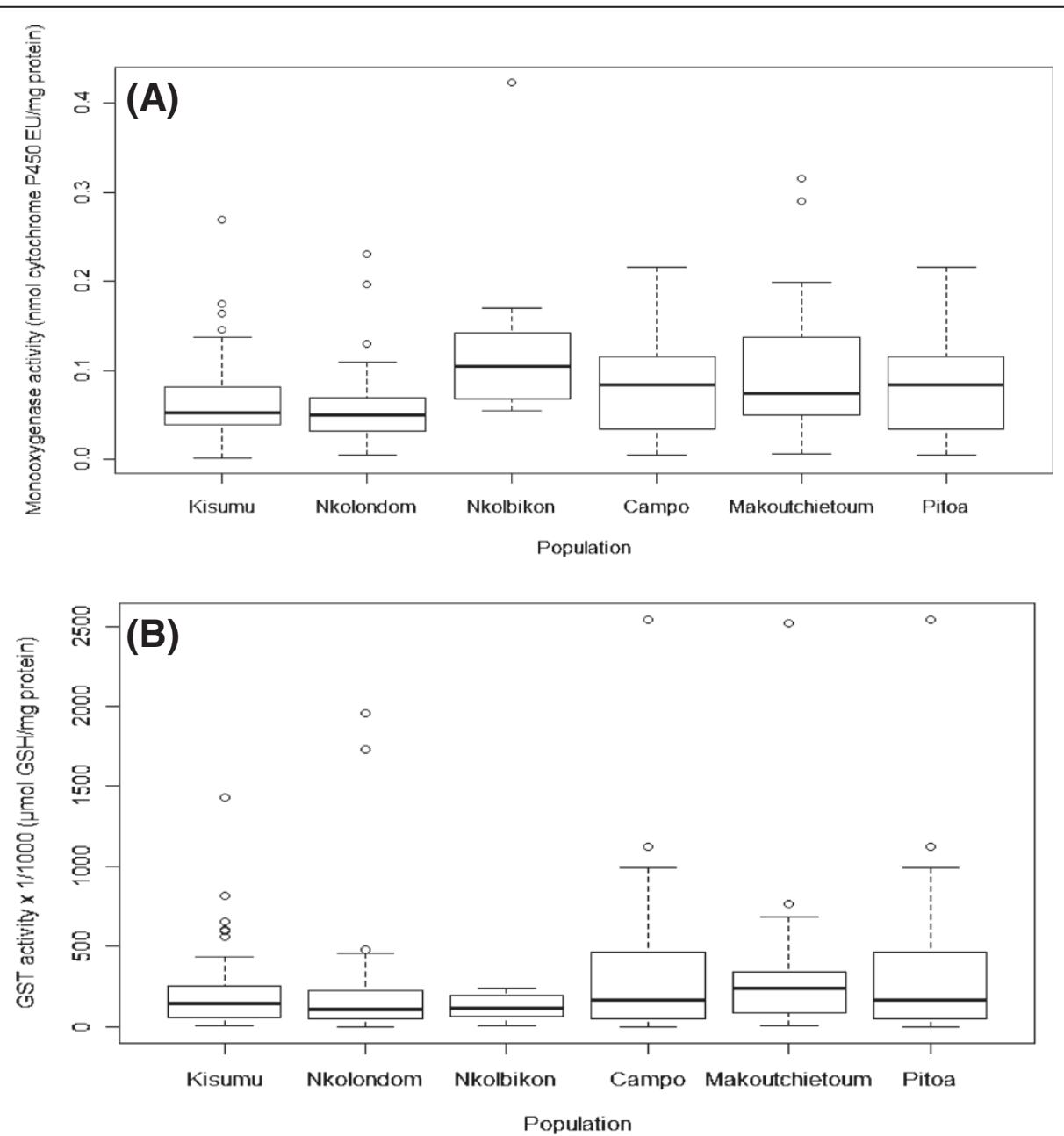

Figure 4 Mean level of detoxifying enzyme activity in field-collected Anopheles gambiae s.l. from Cameroon. (A) Mixed function oxidases (MFOs); (B) Glutathion S-transferases (GSTs). Kisumu refers to the reference susceptible strain of An. gambiae s.s used as control. 
also consistent with previous reports $[14,18,28]$. In many cases, exposing mosquitoes to synergists (i.e. DEF, DEM and $\mathrm{PBO}$, respectively) prior to insecticides partially restored insecticide knockdown effect and increased mortality rates in standard WHO assays, suggesting a role of detoxifying enzymes (i.e. NSEs, GSTs and MFOs, respectively) in increasing mosquito survival upon challenge by permethrin, deltamethrin and, to a lower extent, DDT. Molecular and biochemical investigations further revealed a complex interplay between molecular (i.e., $k d r$-based) and metabolic (i.e., enzyme-based) resistance mechanisms in mosquitoes surviving insecticide exposure. Table 3 shows a qualitative summary of the different putative resistance mechanisms that were evidenced in this study, based on i) synergist bioassays results, ii) detection of $k d r$ resistant alleles and iii) biochemical assessment of detoxifying enzyme activities (e.g., NSEs and MFOs). Multiple resistance mechanisms segregated in the $\mathrm{S}$ form of $A n$. gambiae resulting in heterogeneous resistance profiles, whereas in the $\mathrm{M}$ form and $\mathrm{An}$. arabiensis insecticide tolerance seems to be essentially mediated by enzyme-based detoxification.

Several approaches may be used to investigate mechanisms of insecticide resistance in a vector population. So far, cross-resistance to commonly used classes of insecticides based on bioassay data has been suggested to depict resistance mechanisms [29], but this approach does not provide irrefutable evidence when metabolic resistance and target-site insensitivity interact in a particular population. The entry point of an investigation on multiple mechanisms is the co-formulation of synergists with the insecticide to counteract metabolic resistance. Synergists act by blocking metabolic pathways that would otherwise break down insecticides, then restore the susceptibility to the insecticide [30-32]. Using synergists in the current study allowed gaining preliminary information on metabolic resistance mechanisms coinvolved with $k d r$ mutations in An. gambiae s.l. resistance in Cameroon.

Complete or partial DDT and permethrin resistance suppression was achieved in the presence of the three synergists in the Campo sample, suggesting a major role for metabolic processes in shaping the resistance phenotype of this mosquito population encompassing both $A n$. gambiae $\mathrm{S}$ and $\mathrm{M}$ molecular forms. In other populations such as in Nkolondom and Makoutchietoum where only the $S$ form survived insecticide exposure, the resistance level to DDT was not affected by synergists, suggesting no role for metabolic resistance mechanisms and a major effect for $k d r$ alleles in shaping resistance to DDT in these populations [18,28]. Pre-exposure to synergists, however, restored susceptibility to pyrethroids in Makoutchietoum, reflecting an impact of metabolic processes in pyrethroid resistance, whereas high initial mortality to both permethrin and deltamethrin in Nkolondom suggested absence of metabolic detoxification in this latter population.

The synergistic effects of PBO were noticed with all three insecticides (deltamethrin, permethrin and DDT to some extent). These observations are consistent with previous reports on the mode of action and synergist efficacy of PBO [33-36] and agree with a predominant position of $\mathrm{PBO}$ in synergizing a wide range of insecticides including organophosphates, carbamates, pyrethrins and pyrethroids [37,38]. Furthermore, high level activity of cytochrome P450s (i.e., MFOs) was detected in most of the An. gambiae s.l. populations surveyed, confirming their involvement in the phenotype

Table 3 Putative insecticide resistance mechanisms identified in different An. gambiae s.l. populations from Cameroon

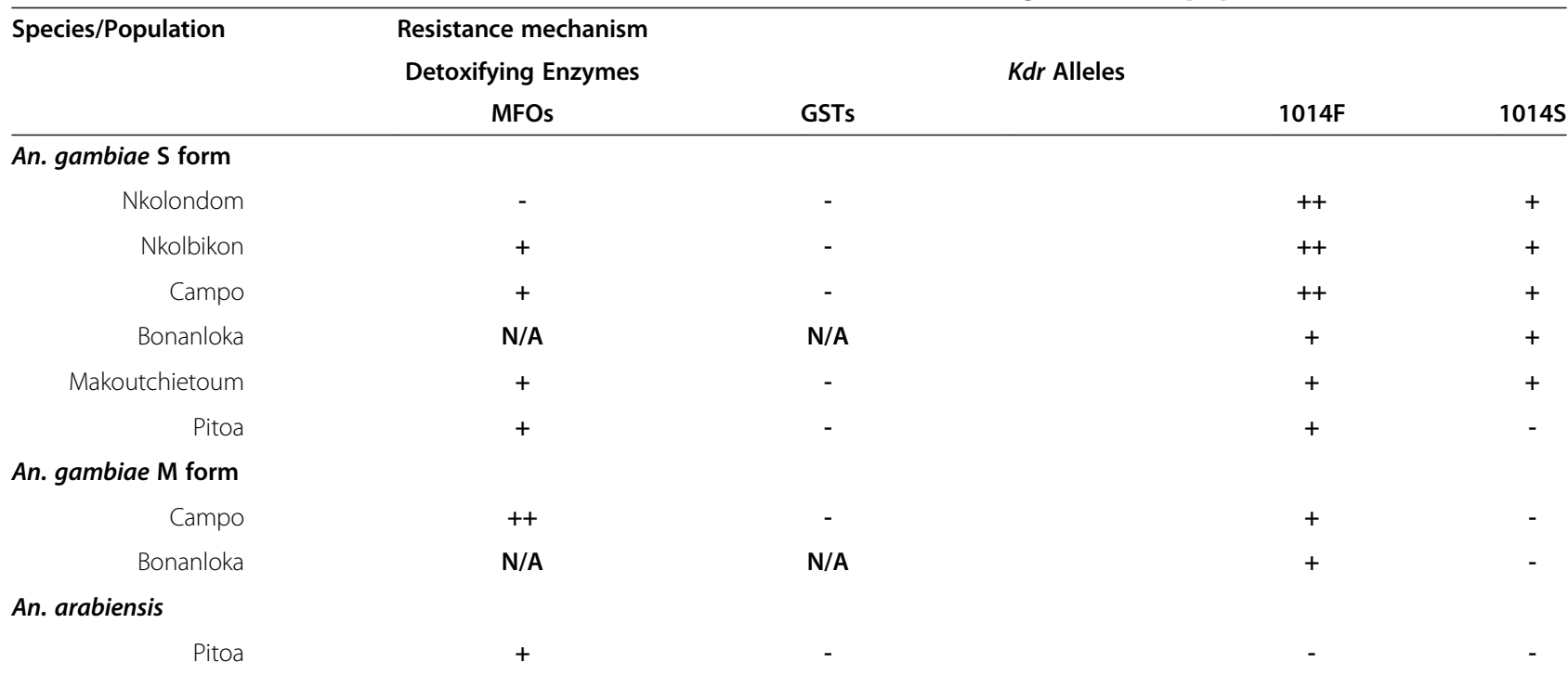

++: Major role in resistance; +: Presence; -: Not observed in this study; N/A: Not determined. 
of resistance as revealed by bioassay tests with synergists. These data complement previous reports on metabolic based insecticide resistance in An. gambiae s.s. from Cameroon [12,13]. Overexpression of P450s enzymes has been found to play a major role in pyrethroid resistance in insects [39-41]; likewise, high level GSTs activity was reported to be associated with insect resistance to DDT and pyrethroids [42-44]. Both bioassay and biochemical data presented in this study are congruent with the first observation but not with the second. The absence of correlation between low levels of GST activity and DDT resistance may be due to the involvement of $k d r$ mutations as the major DDT resistance mechanism in tested mosquito populations. Because it is known that $\mathrm{PBO}$ inhibits $\mathrm{P} 450$ s that mediate resistance to all classes of insecticides $[45,46]$ and to the well known organochlorine DDT $[47,48]$, our findings suggest that, when this synergist is associated with deltamethrin, it could be efficiently used for malaria vector control interventions as reported in recent studies $[49,50]$. The potent possibility of $\mathrm{PBO}$ as an effective synergist for deltamethrin has also been reported against Aedes and Culex genera, suggesting its wide range of action in several mosquito species [36]. Even though the activity of NSEs was not assessed in the framework of this study, bioassay data revealed that DEF was also an effective synergist to suppress pyrethroid resistance in at least some of the $A n$. gambiae s.l. populations sampled. Moreover, in previous studies, NSEs were shown to be inhibited by PBO [51-53] and it is therefore possible that NSEs further contribute to insecticide resistance in Cameroon. However, it is clear that the effects of DEF, DEM and PBO as shown in the current study did not reveal the specificity between each synergist and a given enzyme family. Pasay et al. [32] concluded that, the metabolic routes blocked by synergists are not yet fully understood and may be dependent on the species of arthropods. Hence, further investigations are needed to evaluate the level of involvement of each enzyme family in the overall metabolic-based resistance observed in An. gambiae s.l. populations from Cameroon.

\section{Conclusion}

The current study revealed the simultaneous presence of multiple resistance mechanisms in the malaria vector An. gambiae s.l. populations from Cameroon, a pattern that likely holds true for most parts of West and Central Africa [54-57]. The co-occurrence and co-implication of both metabolic- and $k d r$-based resistance mechanisms in An. gambiae s.l is a serious threat to the effectiveness of current malaria vector control operations based on LLINs and IRS. Because malaria is a devastating disease with considerable impact on human health in Cameroon and beyond [58] urgency might require the use of synergists to mitigate insecticide resistance in major malaria vector mosquitoes. However, alternative innovative vector control tools and solutions are urgently needed to complement or even replace insecticide-based strategies in order to face the challenge of global malaria elimination $[5,59]$.

\section{Competing interests}

The authors declare that they have no competing interests.

\section{Authors' contributions}

JE and FS conceive the study. JE, FS, RM, and PN designed the study protocol; JE, PN, MC and JCT, performed field work and bioassays; PN and AK have performed molecular and biochemical analyses; PN and JE analyzed and interpreted the data; PN drafted the manuscript which was critically revised by JE, RM and FS. All the authors read and approved the final manuscript.

\section{Acknowledgements}

We wish to thank Bertrand Feshu, Souleymanou, and the communities in our study sites for their help and collaboration in the field.

\section{Author details}

${ }^{1}$ Organisation de Coordination pour la lutte contre les Endémies en Afrique Centrale, P.O. Box 288, Yaoundé, Cameroon. '2Université de Yaoundé I, Yaoundé, Cameroon. ${ }^{3}$ Faculty of Medicine and Pharmaceutical Sciences, University of Douala, Douala, Cameroon. ${ }^{4}$ Institut Pierre Richet (IPR), BP 47, Abidjan, Côte d'Ivoire. ${ }^{5}$ MIVEGEC (UMR IRD224-CNRS5290-UM1-UM2), Institut de Recherche pour le Développement (IRD), Montpellier, France.

Received: 22 November 2012 Accepted: 15 February 2013

Published: 22 February 2013

\section{References}

1. WHO: Global strategic framework for integrated vector management. Geneva, Switzerland: $\mathrm{WHO} ; 2004$

2. Townson $H$, Nathan MB, Zaim M, Guillet $P$, Manga $L$, Bos R, Kindhauser M: Exploiting the potential of vector control for disease prevention. Bull World Health Organ 2005, 83:942-947.

3. WHO: Test procedures for insecticide resistance monitoring in malaria vectors, bio-efficacy and persistence of insecticides in treated surfaces, WHO/CDS/CPC/ MAL/98.12. Geneva, Switzerland: WHO, Control of Communicable Diseases (CDS) Prevention and Control; 1998.

4. WHO: Indoor residual spraying: use of indoor residual spraying for scaling up malaria control and elimination. Geneva, Switzerland: World Health Organization; 2008.

5. Feachem R, Sabot O: A new global malaria eradication strategy. Lancet 2008, 371:1633-1635.

6. WHO: World malaria report 2009. Geneva: World Health Organization; 2009:40.

7. Overgaard HJ, Reddy VP, Abaga S, Matias A, Reddy MR, Kulkarni V, Schwabe C, Segura L, Kleinschmidt I, Slotman MA: Malaria transmission after five years of vector control on Bioko island, Equatorial Guinea. Parasites Vectors 2012, 5:253.

8. Bhattarai A, Ali AS, Kachur P, Martensson A, Abbas AK, Khatib R, Almafazy A, Ramsan M, Rotllant G, Gerstenmaier JF, Molteni F, Abdulla S, Montgomery SM, Kaneko A, Bjorkman A: Impact of artemesinin-based combination therapy and insecticide-treated nets on malaria burden in Zanzibar. Plos Med 2007, 4:e309.

9. Okumu FO, Moore SJ: Combining indoor residual spraying and insecticide-treated nets for malaria control in Africa: overview of possible outcomes and an outline of suggestions for the future. Malaria $J$ 2011, 10:208.

10. Etang J, Nwane P, Mbida JA, Piameu M, Manga B, Souop D, AwonoAmbene $P$ : Variations of insecticide residual bio-efficacy on different types of walls: results from a community-based trial in south Cameroon. Malaria J 2011, 10:333.

11. Etang J, Fondjo E, Chandre F, Brengues C, Nwane P, Chouaïbou M, Ndjemai $\mathrm{H}$, Simard F: First report of knockdown mutations in the malaria vector anopheles gambiae from Cameroon. AmJTrop Med Hyg 2006, 74:795-797. 
12. Müller $P$, Chouaïbou M, Pignatelli $P$, Etang J, Walker ED, Donnelly MJ, Simard $\mathrm{F}$, Ranson $\mathrm{H}$ : Pyrethroid tolerance is associated with elevated expression of antioxidants and agricultural practice in anopheles arabiensis sampled from an area of cotton fields in northern Cameroon. Mol Ecol 2008, 17(4):1145-1155

13. Etang J, Manga L, Toto JC, Guillet P, Fondjo E, Chandre F: Spectrum of metabolic-based resistance to DDT and pyrethroids in anopheles gambiae s.l populations from Cameroon. J Vect Ecol 2007, 32(1):123-133.

14. Nwane P, Etang J, Chouaïbou M, Toto JC, Mimpfoundi R, Simard F: Kdrbased insecticide resistance in anopheles gambiae s.s populations in Cameroon: spread of the L1014F and L1014S mutations. BMC Res Notes 2011, 4:463.

15. Brooke BD: Kdr: can a single mutation produce an entire insecticide resistance phenotype? Trans Roy Soc Trop Med Hyg 2008, 102:524-525.

16. Donnelly MJ, Corbel V, Weetman D, Wilding CS, Williamson MS, Black WC IV: Does $k d r$ genotype predict insecticide-resistance phenotype in mosquitoes. Trends Parasitol 2009, 25(5):213-219.

17. Ramphul U, Boase T, Bass C, Okedi LM, Donnelly MJ, Müller P: Insecticide resistance and its association with target-site mutations in natural populations of anopheles gambiae from eastern Uganda. Trans Roy Soc Trop Med Hyg 2009, 103:1121-1126.

18. Nwane P, Etang J, Chouaibou M, Toto JC, Kerah-Hinzoumbé C, Mimpfoundi $\mathrm{R}$, Awono-Ambene HP, Simard F: Trends in DDT and pyrethroid resistance in anopheles gambiae s.s. Populations from urban and agro-industrial settings in southern Cameroon. BMC Infect Dis 2009, 9:163.

19. Chouaïbou M, Etang J, Brevault T, Nwane P, Hinzoumbé CK, Mimpfoundi R, Simard F: Dynamics of insecticide resistance in the malaria vector anopheles gambiae s.I from an area of extensive cotton cultivation in northern Cameroon. Trop Med Int Health 2008, 13(4):1-11.

20. Gillies MT, De Meillon B: The anophelinae of Africa south of the Sahara. Publ South African Institute Med Res 1968, 54:343p.

21. Gillies MT, Coetzee M: Supplement to the anophelinae of Africa south of the Sahara (afrotropical region). South African Institute Med Res 1987, 55:143.

22. Collins FH, Mendez MA, Razmussen MO, Mehaffey PC, Besansky NJ, Finnerty VA: Ribosomal RNA gene probe differentiates member species of Anopheles gambiae complex. AmJTrop Med Hyg 1987, 37:37-41.

23. Fanello C, Santolamazza F, Ddella Torré A: Simultaneous identification of species and molecular forms of the Anopheles gambiae complex by PCRRFLP. Med Vet Entomol 2002, 16:461-464.

24. Lynd A, Ranson H, McCall PJ, Randle NP, Black WC IV, Walker ED, Donnelly MJ: A simplified high-throughput method for pyrethroid knockdown resistance $(k d r)$ detection in anopheles gambiae. Malaria J 2005, 4:16.

25. Hemingway J: Techniques to detect insecticide resistance mechanisms (Field and laboratory manual). Document WHO/CDS/CPC/MAL/98.6. Geneva, Switzerland: World Health Organ; 1998.

26. Finney DJ: Probit analysis. 3rd edition. Cambridge, UK: Cambridge University Press; 1971:333.

27. Thomas A, Kumar S, Pillai MMK: Pyperonyl butoxide as a counter measure for deltamethrin resistance in Culex quinquefasciatus Say. Entomon 1991, 18:1-10.

28. Antonio-Nkondjio C, Tene Fossog B, Ndo C, Menze Djantio B, Zebaze Togouet S, Awono-Ambene P, Costantini C, Wondji C, Ranson H: Anopheles gambiae distribution and insecticide resistance in the cities of douala and Yaoundé (Cameroon): influence of urban agriculture and pollution. Malaria J 2011, 10:154

29. Brodgon WG, MCAllister JC, Vulule J: Heme peroxydase activity measured in single mosquitoes identifies individuals expressing an elevated oxidase for insecticide resistance. J Am Mosq Control Assoc 1997 13:233-237.

30. Casida JE: Mixed-function oxydases involvement in the biochemistry. J Agric Food Chem 1970, 18:753-772.

31. Jao LT, Casida JE: Insect pyrethroid-hydrolyzing esterases. Pestic Biochem Physiol 1974, 4:465-472.

32. Pasay C, Arlian L, Morgan M, Gunning R, Rossiter L, Holt D, Walton S, Beckman S, McCarthy J: The effect of insecticide synergists on the response of scabies mites to pyrethroid acaricides. PLoS Negl Trop Dis 2009, 3:e354.

33. Farnham AW: The mode of action of piperonyl butoxide with reference to studying pesticide resistance. In Piperonyl butoxide: the insecticide synergist. Edited by Jones DG. London: Academic; 1998:199-214.
34. Pap L, Arvai G, Bertok B, Kuruczne RZ, Bakonyvari l: Comparative of new synergists containing a butynyl-type synergophore group and piperonyl butoxide derivatives. Pest Manag Sci 2001, 57:186-190

35. Fakoorziba MR, Eghbal F, Vijayan VA: Synergist efficacy of piperonyl butoxide with deltamethrin as pyrethroid insecticide on Culex tritaeniorhyncus (diptera: culicidae) and other mosquito species. Environ Toxicol 2008, 24:19-24.

36. Cakir G, Yavuz O, Kokak O: Effects of piperonyl butoxide and tetramethrin combinations on biological activities of selected synthetic pyrethroid insecticides against different housefly (musca domestica L., diptera: muscidae) populations. Acta Veterinaria Brno 2008, 77:464-474.

37. Tomlin CSD: The pesticide manual. 11th edition. Farnham: British Crop Protection Council; 1997:1606.

38. Kaene $P$ : The use of piperonyl butoxide in formulations for the control of pests of humans, domestic and food animals. In Piperonyl butoxide: the insecticide synergist. Edited by Jones DG. London: Academic Press London; 1998:289-300.

39. Feyereisen R: Insect P450 enzymes. Annu Rev Entomol 1999, 44:507-533.

40. Kasai S, Scott JD: Over expression of cytochrome P450 CYP6D1 is associated with monooxygenases-mediated pyrethroid resistance in house flies from Georgia. Pestic Biochem Physiol 2000, 68:34-41.

41. Hemingway J, Hawkes NJ, McCarroll L, Ranson H: The molecular basis of insecticide resistance in mosquitoes. Insect Biochem Mol Biol 2004, 34:653-666.

42. Vontas JG, Small GJ, Hemingway J: Glutathione S-transferase as anti oxidant defence agents confer pyrethroids in Nilaparvata lugens. Biochem J 2001, 357:65-72.

43. Grant DF, Dietze EC, Hammock BD: Glutathione S-transferase isozymes in aedes aegypti purification, characterization and isozyme-specific regulation. Insect Biochem 1991, 21:421-433.

44. Zhou ZH, Syvanen M: A complex glutathione transferase gene family in the housefly musca domestica. Mol Gen Genet 1997, 256:187-194.

45. Hodgson E, Levi PE: Interactions of piperonyl butoxide with cytochrome P450. In Piperonyl butoxide: the insecticide synergist. Edited by Jones DG. London: Academic Press; 1998:41-53.

46. Kumar S, Thomas A, Sahgal A, Verma A, Samuel T, Pillai MK: Effect of the synergist, piperonyl butoxide on the development of resistance in yellow fever mosquito, Aedes aegypti L, (Diptera: Culicidae). Arch Insect Biochem Physiol 2002, 50:1-8.

47. Chung H, Bogwitz MR, McCart C, Andrianopoulos A, French-Constant RH, Batterham P, Daborn PJ: Cis-regulatory elements in the accord retrotransposon result in tissue-specific expression of the drosophila melanogaster insecticide resistance gene Cyp6g1. Genetics 2007, 175:1071-1077.

48. Chiu TL, Wen Z, Rupasinghe SG, Schuler MA: Comparative molecular modelling of anopheles gambiae CYP6Z1, a mosquito P450 capable of metabolizing DDT. Proc Natl Acad Sci 2008, 105:8855-8860.

49. Corbel V, Chabi J, Dabiré RK, Etang J, Nwane P, Pigeon O, Akogbéto M, Hougard JM: Field efficacy of a new mosaic long lasting mosquito net (PermaNet ${ }^{\circledR} 3.0$ Against pyrethroid-resistant malaria vectors: a multi centre study in western and central Africa. Malaria J 2010, 9:113.

50. Yewhalaw D, Asale A, Tushune K, Getachew Y, Duchateau L, Speybroeck L: Bio-efficacy of selected long-lasting insecticidal nets against pyrethroid resistant anopheles arabiensis from south-western Ethiopia. Parasites Vectors 2012, 5:159.

51. Gunning RB, Moores GD, Devonshire AL: Inhibition of resistance-related esterases by piperonyl butoxide in helicoverpa armigera (Lepidoptera: noctuidae) and aphis gossypi (hemiptera: aphididae, pp. 215-226. In Piperonyl butoxide. Edited by Jones DG. San Diego, CA: Academic; 1998.

52. Young SJ, Gunning RV, Moores GD: The effect of pyperonyl butoxide on pyrethroid-resistance associated esterases in helicoverpa armigera (hubner) (Lepidoptera; noctuidae). Pest Manag Sci 2005, 61:397-401.

53. Khot AC, Bingham G, Field LM, Moores GD: A novel assay reveals the blockade of esterases by piperonyl butoxide. Pest Manag Sci 2008, 64:1139-1142

54. Kerah-Hinzoumbé C, Péka M, Nwane P, Donan-Gouni I, Etang J, Samè-Ekobo A, Simard F: Insecticide resistance in Anopheles gambiae from southwestern Chad, Central Africa. Malaria J 2008, 7:192.

55. Djègbè I, Olayidé B, Aboubakar S, Thibaud M, Ranson H, Chandre F, Akogbéto $M$, Corbel V: Dynamics of insecticide resistance in malaria vectors in Benin: first evidence of the presence of L1014S kdr mutation in anopheles gambiae from west Africa. Malaria J 2011, 10:261. 
56. Namountougou M, Simard F, Baldet T, Diabaté A, Ouédraogo JB, Martin T, Dabiré RK: Multiple insecticide resistance in anopheles gambiae s.l.

Populations from Burkina Faso, west Africa. PLOS One 2012, 7(11):e48412.

57. Basilua Kanza JP, El Fahime E, Alaoui S, Essassi M, Brooke B, Nkebolo Malafu A, Watsenga Tezzo F: Pyrethroid, DDT and malathion resistance in the malaria vector anopheles gambiae from the democratic republic of Congo. Trans Roy Soc Trop Med Hyg 2013, 107(1):8-14.

58. WHO: World malaria report 2012. Geneva: World Health Organization; 2012:195.

59. Takken W, Knols BGJ: Malaria vector control: current and future strategies. Trends Parasitol 2009, 25(3):101-104.

doi:10.1186/1756-3305-6-41

Cite this article as: Nwane et al:: Multiple insecticide resistance mechanisms in Anopheles gambiae s.l. populations from Cameroon, Central Africa. Parasites \& Vectors 2013 6:41.

\section{Submit your next manuscript to BioMed Central and take full advantage of:}

- Convenient online submission

- Thorough peer review

- No space constraints or color figure charges

- Immediate publication on acceptance

- Inclusion in PubMed, CAS, Scopus and Google Scholar

- Research which is freely available for redistribution 